\title{
ANNOTATION
}

\section{On the Invention of Ophthalmic Instruments}

Many surgeons of great and deserved repute have invented each a single instrument, such as Beer's knife or Tyrrell's hook; and some have invented more than one. So wrote Brudenell Carter in 1875 and he went on, in his most sarcastic vein, to refer to the gift of fingers and of a man being able to use the instruments invented by others rather than venturing into such pastures new for himself. The writer of this note never invented an instrument in his life but has always had a sort of sneaking admiration for those who do. Think for a moment of Scott's cataract knife, described in our pages in Vol. XI. "The back of the knife describes a sixth part of the circumference of a circle the radius of which is ten lines. The chord of the arc formed by the back of the knife is, of course, also ten lines in length, being equal to the radius of the circle; it is therefore greater by four lines than the diameter of the cornea "

To our own non-mathematical mind this is very nearly as perplexing as the "thorny and bewildered track" in which Uncle Toby found himself after studying Malthus ("Fireworks" not "Population" Malthus) Galileo and Torricellius, on the geometrical rules laid down to show which way a cannon ball went after being shot from the cannon's mouth.

The mathematics of Scott's knife seem unobjectionable, but we believe it never came into general use. The same applies to a knife which was invented by a much respected friend of ours for the manufacture of artificial pupils in dense after cataracts and in cases of up-drawn iris. The mathematics of this knife we have forgotten but .we remember that we rather irreverently nicknamed it "the bill-hook." It worked very well at its first trial, but alas, at a later performance the iris was torn from its base over a half of its circumference. The anterior chamber filled up with blood in a flash. No artificial pupil resulted though the eye quietened down slowly and the "bill-hook" disappeared from our friend's armamentarium.

It is not given to everyone to design new instruments and most of us may well be thankful if we can use those already on the market in a reasonably capable manner. 